\section{TYPE 1 DIABETES MELLITUS IN CHILDREN : AN ANALYTIC FOLLOW UP STUDY AT A DISTRICT LEVEL GENERAL HOSPITAL, UK}

N. Ganjoo ${ }^{1}$, N. Gupta², S. Mukherji ${ }^{3}$

${ }^{1}$ Department of Paediatrics, ${ }^{2}$ Department of Neonatology, Rosie Unit, Addenbrookes Hospital, Cambridge, ${ }^{3}$ Department of Paediatrics, Colchester University Hospitals NHS Trust, Colchester, UK

Introduction: Diabetes mellitus Type 1 is a common chronic disease that affects children and periodic out patient follow up minimizes the long term complications. This study analysed the follow up protocol for children with type 1 diabetes mellitus in the paediatric out patients, at a District General Hospital.

Method: Retrospective study, between 2008-2009, was conducted of all diabetic children who attended the out patient. The inclusion criteria required the children to be diabetic for at least a year. The data was obtained from the clinical notes and laboratory reports. Details with respect to age, sex, yearly thyroid function tests, HbA1c reports per year and three yearly coeliac screen documented were recorded. For children above 12 years, documented yearly BP record, annual microalbuminuria check and annual retinopathy screening were recorded, as per NICE guidelines, UK.

Result: Of the twenty children, 10 were over 12 years and the remaining 10 above 12 years age. The male to female ratio was $1: 1$. Two HbA1C reports/year were documented for 13 /20 children $(65 \%)$, annual thyroid function tests and the three yearly coeliac screen were documented for $18 / 20$ (90\%)respectively. Of the children above 12 years, $10 / 10(100 \%)$ had annual BP records, 6/10 (60\%) had annual checks for microalbuminuria but only $2 / 10(20 \%)$ had documented retinopathy screen.

Conclusions: The study indicates a satisfactory level of follow up to ascertain possible long term complications and target organ involvement. The retinopathy screening for children above 12 years, indicated a low level of documentation and this needs more attention.

\section{PROBLEM OF OBESITY IN CHILDREN AND YOUTH IN CANTON SARAJEVO}

S. Dinarević, S. Hasanbegovic

Paediatric Clinic Clinical Centre of University Sarajevo, Sarajevo, Bosnia-Herzegovina

Epidemy of obesity in children is one of the most serious health problems of modern world.

The aim of this study was to evaluate the prevalence of obesity in children and youth in Canton Sarajevo.

Participants and methods: Research was conducted among the pupils of primary and secondary schools via measurements of antropometric parameters, calculating body mass index and classifing it according to criteira of Center for control and disease prevention (CDC). Participants answered the questions on quality and quantity of food and liquide intake, frequency and lenght of physical activities or nonactivities in original designed questioneries.

Results: Investigation lasted from 2008-2009., included 3608 pupils, from 9 primary and 6 secondary schools. $1 / 5$ of participants were obese $8 \%, 12.49 \%$ were undernurished. Ideal body weight had $68.74 \%$ pupils. $42.47 \%$ had taken food from bakery. A part of water $(51,82 \%)$ they consumed nonsparkling jouices (20.65\%). 58.15\% eat sweets every day, in secondary school $80,85 \%$. Only $1 / 3$ of pupils, every day participanted in sport, 8.51 $\%$ rarely participate. The least active were pupils from primary, and most active were from secondary school. Even $27,56 \%$ of them are sitting in front of televison or computer, for 2 or more hours daily.

Conclusion: The most important factors which influence the obesity are the sedantary way of life, high frequency of sweets and jouices intake and non adequate food intake in schools. Preventive accitivities should continously be carried out in order to decrease the number of cardiovascular and other disease 